\title{
Advocacy Coalition by External Actors and Strategies Used to Influence the Emergence of the National Nutrition Policy in Lao PDR
}

\section{Viengsamay Sengchaleun ${ }^{1,2 *}$, Mamane Abdoulaye Samri², Sengchanh Kounnavong3, Daniel Reinharz ${ }^{1}$}

\author{
${ }^{1}$ Department of Social and Preventive Medicine, Laval University, Quebec City, Canada \\ ${ }^{2}$ Faculty of Nursing, Laval University, Quebec City, Canada \\ ${ }^{3}$ Lao Tropical and Public Health Institute, Vientiane, Lao PDR \\ Email: *viengsamay.sengchaleun.1@ulaval.ca
}

How to cite this paper: Sengchaleun, V., Samri, M.A., Kounnavong, S. and Reinharz, D. (2021) Advocacy Coalition by External Actors and Strategies Used to Influence the Emergence of the National Nutrition Policy in Lao PDR. Health, 13, 812-829.

https://doi.org/10.4236/health.2021.138062

Received: June 28, 2021

Accepted: August 7, 2021

Published: August 10, 2021

Copyright $\odot 2021$ by author(s) and Scientific Research Publishing Inc. This work is licensed under the Creative Commons Attribution International License (CC BY 4.0).

http://creativecommons.org/licenses/by/4.0/

\begin{abstract}
This article aims to explore the coalition of external actors and the strategies it deployed to influence the emergence of the National Nutrition Policy (NNP) in Lao People's Democratic Republic (Lao PDR). The Advocacy Coalition Framework and the conceptual model of Effective Advocacy Strategies for Influencing Government Nutrition Policy were used to frame the data collection and their analysis. Sources of information were semi-structured interviews conducted with government and external actors, as well as all available documents on nutrition policy in Laos. The commitment of the government to achieve the Millennium Development Goals (MDGs) and to leave the Least Developed Country status created a favorable condition to support the emergence of the NNP in Laos. This context was a driving force for the building of an effective and convincing coalition of United Nations agencies able to accompany the government in redefining health priorities. Various strategies were used by the coalition to this end, including generating, disseminating, and using scientific evidence, assisting the government with a budget and technical expertise, providing decision-makers with opportunities to learn from other countries, and building relationships with the key actor. External actors can be a major force to support the emergence of a public policy in Laos, but this requires a window of opportunity like what the MDGs have been able to bring.
\end{abstract}

\section{Keywords}

External Actors, Advocacy Coalition, Strategy Influence, Nutrition Policy, Lao PDR 


\section{Introduction}

Nutrition is a determinant of the ability to fully benefit from one's potential at birth. Nutrition that answers children's nutritional needs reduces morbidity and mortality, reduces the risk of chronic diseases later in life, and promotes an overall healthy development [1].

In most low and middle-income countries (LMICs), many children do not receive the food needed to answer their development needs. Consequently, they suffer from malnutrition. According to the World Health Organization (WHO), malnutrition is defined as deficiencies, excesses, or imbalances in a person's intake of energy and/or nutrients. There are three main types of malnutrition: 1) protein-energy deficiency, which is the main cause of stunting (low height-for-age), wasting (low weight-for-height) and underweight (low weight-for-age) in children; 2) micronutrient deficiencies (lack of essential vitamins and minerals); 3) overweight [2]. In this study, the term malnutrition refers to protein-energy deficit and micronutrient deficiencies.

Many LMICs have national public policies that cover nutrition issues, particularly undernutrition, infant and young child nutrition, and vitamins and minerals deficiencies [3]. According to the WHO, "A policy is a written statement of commitment (generally in broad terms) by a nation-state". National policies to combat malnutrition represent, formally, a commitment from governments to act [3].

Lao PDR (Laos) enacted its National Nutrition Policy (NNP) in 2008 [4]. Before having an NNP, the country presented high rates of protein-energy malnutrition and micronutrient deficiencies (iodine, vitamin A, and iron). The National Health Survey conducted in 1993 showed that 95\% of the Lao population was iodine-deficient [5], nearly half of the children under 5 years old had a vitamin A deficiency, and half suffered from anemia/iron deficiency [6]. Breastfeeding practice was not optimal, with less than one-third of children less than 4 months of age being exclusively breastfed. Preventable parasitic infections were identified as an important cause of malnutrition. In some areas, the rate of parasite infection among children was estimated at 96\% [6] [7]. About 10 years later, the Multiple Indicator Cluster Survey III (MICS III) in 2006 estimated stunting to affect $40 \%$ of Lao children under the age of five, underweight $37 \%$, and wasting 7\% [8]. These data suggested that Lao children suffered above all from chronic malnutrition. This situation led, since the 1990s, to the design and implementation of various nutrition programs, such as universal salt iodization, vitamin A and iron supplementation, deforming, and the promotion of breastfeeding [9]. It is claimed that external actors played a crucial role in the process of some of these health policies, decrees, and laws [10] [11].

Policymaking is a complex process that involves many participants, each of them with his own roles, interests, and resources [12]. According to Lemieux, "the emergence of policies is the process by which situations perceived to pose 
public problems are put on the agenda of the government or other official body for the purpose of regulation" [13]. It is generally accepted that the emergence of a policy is a crucial stage in the political process. It is where policy options are explored, evaluated, and then accepted, adapted, or rejected by decision-makers. This step involves many and diverse actors who interact, often under intense and targeted political pressure from special advisers, lobbyists, and interest groups. This step, if it is conclusive, leads to the formulation of a policy [13].

In LMICs, foreign external actors as non-governmental organizations (NGOs), United Nations (UN) agencies, and donors can be influential in stimulating the development of a policy and imprinting the policy with a given orientation [14] [15] [16] [17] [18]. This is especially the case when the country has little expertise and few material and human resources and when these actors are an important source of external funding [16] [19]. These actors generally also have skills in research and evaluation, and therefore in the production of scientific information, which makes them capable of articulating the merits of their proposals in connection with the emergence of a policy [17]. In addition, studies on this topic have concluded that the influence of these external actors lies on the financial and expert assistance they provide, but also in their capacity to broker alliances between stakeholders [17] [20].

In this article, we aim to 1) explore the structure and membership (organizational) of the advocacy coalition of external actors involved in the emergence of the NNP in the Lao PDR and 2) the strategies used by these external actors to influence the emergence of the NNP.

\section{Methods}

\subsection{Conceptual Framework}

The conceptual framework used in this study was based on two frameworks: 1) the Advocacy Coalition Framework (ACF) [21] to study how competition between actors influenced the emergence of the Lao public policy on nutrition and 2) the conceptual model of Effective Advocacy Strategies for Influencing Government Nutrition Policy [22] for assessing the strategies used to influence the government.

In the perspective of $\mathrm{ACF}$, a public policy process is a complex process that involves numerous actors, each of them having his values/interests, perceptions of the situation, and his own political preferences. These actors see public policies as a tool to satisfy some of their interests. To increase the probability to put these interests inside a policy, they tend to gather in coalitions, i.e. groups that collaborate to reach a common objective [21] [23]. There are different reasons for participation in a coalition. Members can be willing to participate because they share an ideology or values. They can seek to be part of a coalition because it might provide resources of interest that are detained by other members. They can also sometimes be forced to participate in the coalition [24]. In the political 
arena, each coalition has its own points of view or its own beliefs on the problem and how to solve it. Coalitions are therefore in competition to influence the making process of public policies [23].

The interest of ACF is not limited to the study of the emergence of a policy through the interactions between coalitions and the strategies deployed by each of them to advance its own agenda. It will also allow researchers to study the influence of external events on the emergence of a public policy [25].

The Effective Advocacy Strategies for Influencing Government Nutrition Policy developed by Katherine Cullerton in 2018 [22] provides guidance for interpreting the strategies deployed by organizations to influence a nutrition policy-making process. The framework lies on two main elements: contextual factors and enablers. Contextual factors are related to the environment in which the policy development takes place. It allows identifying the "policy window" that triggers the design of advocacy strategies by stakeholders. Enablers are facilitating factors that increase the capacity of stakeholders to influence the policy-making process [22].

These conceptual frameworks seem relevant to study how the various actors in Laos, through coalitions, have given the specific color to the Lao policy against malnutrition. The ACF seemed relevant, because, despite the fact that Laos is a one-party state and this affects the building of coalitions, there is a potential for the emergence of coalitions in the country, particularly among external actors.

\subsection{Data Collection}

This paper used a case study; data were collected between March and June 2020.

Semi-structured interviews were the key data sources. Interviews were performed with the representatives of the organizations active in the fight against malnutrition in Laos before the emergence of the NNP. A "purposeful sampling" approach was first used to identify which organizations should be solicited [26]. This method "consists in selecting certain people according to characteristics typical of the population under study" [26]. It is often used in qualitative research to collect "informative, rich, and meaningful" data. This approach also makes it possible to deliberately constitute a sample as diverse as possible in order to have participants likely to be representative of the diversity of the opinions to be studied and thus be able to meet the objectives of the study [26]. Additional organizations were identified using a snowball procedure [27]. At the end of an interview, the participants were asked to suggest the names of individuals or organizations, likely to provide additional, contradictory, or other information that they have provided. This method was justified by our willingness and need to have information from various sources to cover the different perspectives of the subject. The number of interviews was increased until researchers judged that the saturation of information had been reached.

The choice of the participants was made based on four criteria: 1) the involvement of their organization in the fight against malnutrition; 2) the fact they 
occupied a position in their organization for at least one year, which allowed them to understand the activities deployed in connection with the health of the populations; 3) their knowledge about the involvement of their organization in the fight against malnutrition during the emergence of the nutrition policy; 4) the fact the participation would increase the diversity of opinion and understanding regarding the emergence of the NNP.

Interviews consisted of face-to-face meetings, videoconferences, and phone meetings. Interviews lasted between 45 and $90 \mathrm{~min}$. They were audio-recorded with the consent of the participants. Moreover, handwritten notes were taken during and after the interviews. An interview guide covering the problem of malnutrition in the country was used. Themes of discussion were defined in order to allow extracting information on the dimensions of the conceptual framework. Participants were interviewed about their perception of the evolution of malnutrition in Laos before the emergence of NNP, how external actors influenced the emergence of NNP, and which strategies were used. The interviewer had the flexibility to add or subtract questions, depending on the information generated during the interview.

Interviews were conducted in the language chosen by the interviewee: Lao, English, or French. Recorded interviews were first transcribed in the language of the interview. The interviews in Lao were translated into French by one of the researchers. As soon as a transcript was produced, it was sent to another researcher and discussed in order to adjust the questions to ask for the next interviews, if the last interview had revealed an aspect deemed particularly relevant for the study.

The information provided by the interviews was completed by documents of several types, written in English, Lao, or French dating back to 1990. These documents were published academic literature, the documents received from the respondents, as well as those available on the website of their organization. These documents consisted of the external actors' policies and strategies relating to the emergence of nutrition policy and all available national documents showed how nutrition had been addressed before the emergence of the NNP in Laos.

\subsection{Data Analysis}

Interviews and document content were analyzed using NVivo 11 software (qualitative data analysis software, QSR International Pty Ltd., Australia). The process of analyzing was codification, identifying significant patterns, and finally drawing meaning and building a logical chain of data [28].

The initial coding scheme was based on the conceptual frameworks. It consisted of extracting elements from interviews and documents, in order to categorize, classify and order the data and constitute units of meaning. Themes belonging to the same concept were grouped into a conceptual category. The linking of these conceptual categories was oriented in such a way as to meet the research objectives [29]. 
The analysis was done using an inductive-deductive approach. The coding of data and the evolution of the coding tree were performed by one researcher and were validated by another researcher as the analyses were going along. When disagreement arose or if an external point of view was required, the third researcher was consulted.

\subsection{Ethical Considerations}

The ethical approvals for the study were obtained from the Sectoral Health Sciences Research Ethics Committee of Laval University, Quebec, Canada (number "2020-009/22-01-2020") and the National Ethics Committee for Health Research, Ministry of Health, Vientiane, Lao PDR (number “017/NECHR”, 28/02/2020).

\section{Results}

In total 20 semi-structured interviews were conducted; eight participants didn't answer our solicitation. Sociodemographic, characteristics of participants $(\mathrm{P})$ and interviews are shown in Table 1 .

The following sections present the results about the external event, the coalition of external actors, and the strategies used to influence the emergence of NNP in Laos. Figure 1 outlines the results of the analyses.

Table 1. Sociodemographic, characteristics of participants and interviews.

\begin{tabular}{lc}
\hline Age (years) & 44 \\
Mean & $33-63$ \\
Minimum-maximum & \\
Gender $(\mathbf{n}=20)$ & 6 \\
Male & 14 \\
Female & \\
Organizations of the participants $(\mathbf{n}=20)$ & \\
Government staff (representatives of ministries or institutions & 12 \\
belonging to a ministry) & 3 \\
UN agencies & 3 \\
NGOs & 1 \\
Bi/multi-lateral cooperation & 1 \\
Consultant & 17 \\
Language of interview $(\mathbf{n}=20)$ & \\
Lao & \\
English & \\
French & \\
\hline
\end{tabular}

(n): number of participants. 


\section{$\underline{\text { Relatively stable parameters }}$}

Human right to get adequate food

Malnutrition as an evitable cause of under-five mortality

Gxternal events
Government
- International Conference on Nutrition (1992)
- Endorsement of MDGs (2000)
- National Growth and Poverty Eradication Strategy
(2004-2006)
UN agencies
- UN Common Country Assessment (2004)
- First and second MDG progress report (2004 and 2008)
- UN Development Assistance Framework (2007-2011)
Nutrition specific events
- Lao PDR Multiple Indicator Cluster Survey I, II, and III
(1996, 2000, and 2006)
- National decree on universal salt fortification with iodine
(1995)
- Vitamin A supplementation program for children under 5
years old (1996)
- Iron supplementation tablets to pregnant women at
antenatal care visits (mid-1990)
- Regulations on Infant and Child Food Product Control
- National School Deworming campaign (2005)

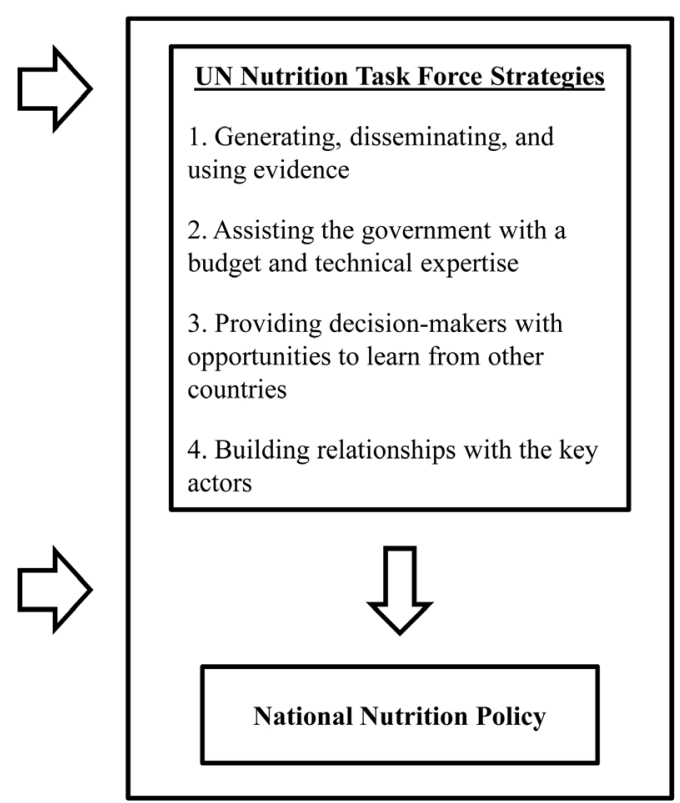

Figure 1. Organizational factors associated with the emergence of National Nutrition Policy in Lao PDR. This figure presents the main observation associated with the dimensions of the conceptual framework. Two major dimensions are considered: the "relatively stable parameters", which represent the fundamental values of the society, and the "external events", which refer to occurrences that influenced the emergence of the NNP. The UN Nutrition Task Force strategies box presents the strategies that the most influential actor deployed to convince the government to enact a national policy on nutrition.

\subsection{External Events Influence the Emergence of National Nutrition Policy}

The major external event that impacted the emergence of the policy was the Commitment by the Lao government to attain the Millennium Development Goals (MDGs) and to leave the Least Developed Country status by 2020 [P1, P2, P7, P14, P15, P18, P20]. Eradication of poverty moved at the center of the country's development plans. The MDGs became the main framework for these development objectives [30].

The nutrition situation before the emergence of the NNP was considered dire. The first and second MDG Progress Reports published in 2004 and 2008, respectively, showed that malnutrition in children under five years old was not improving as expected, despite some interventions that had been implemented. The Reports suggested that poverty reduction only would not automatically improve malnutrition. The conclusion of the Reports became a concern for the govern- 
ment, as they showed that the capacity of the country to reach its poverty eradication objective needed to redefine some priorities and should consider fighting more effectively against malnutrition [31] [32].

"The malnutrition rate in our country was very high, especially the rate of malnutrition in under five-year-old children, there was no improvement during the $1990 s$ and $2000 s$, and had even increased in some rural areas" [P2].

"To exit the Least Developed Country status required not only eradicating poverty but also improving human resources through health, nutrition and education interventions... the government committed to achieving MDGs so it's important to reduce malnutrition in the country" [P7].

\subsection{External Actors Coalition' Influence on the Emergence of National Nutrition Policy}

Indeed, before the emergence of the NNP, there was, at the national government policy levels in Laos, little focus on malnutrition [P1, P2, P5, P7, P15]. The 20062010 five-year National Socio-Economic Plan for example does not mention nutrition issues. Yet, nutrition was not ignored; some nutrition-related decrees, laws, and programs were put in place (see Figure 1). It also appears in documents on poverty where it's defined as a cause and consequence of impoverishment. The 2004-2006 National Growth and Poverty Eradication Strategy for example hints at malnutrition as a determinant of poverty that has to be addressed [33]. Discrepancies regarding the importance of nutrition among governmental priorities seem therefore to reflect that a formal leadership had still to emerge to make the entire Lao government structure becoming conscious about the key role of nutrition in the personal well-being and economic development of the country and the government's responsibility to fight against malnutrition. External actors, in particular the UN agencies that were compelled to orient their programs in order to more effectively support the MDGs, were more sensitive to the importance to make the fight against malnutrition a national priority, hence a leadership in the area of nutrition [P1, P2, P4, P5, P7, P8, P10, P12, P15, P17]. However, at the beginning of the 2000s, they still needed to put in place an inner structure that would help them to become more helpful in supporting the government to assume this leadership. A taskforce that could speak for all the agencies was considered as the tool the most susceptible to reach this objective [P5, P17].

Consistent with our preliminary hypothesis, we found that a coalition of UN agencies preceded and enable the emergence of the NNP. Around the year 2004, a "United Nation Nutrition Task Force" in Laos was put in place. It was created to better support the government to fulfill its commitment to attain the MDGs and to leave the Least Developed Countries category. Its members were the principal agencies concerned by malnutrition: WHO, United Nations Children's Fund (UNICEF), Food and Agriculture Organization (FAO), and World Food Programme (WFP). By building a task force, the UN aimed at exploiting the complementarity between the agencies' expertise in accordance with the UN agencies' mandates to collaborate one with another in order to achieve more ef- 
ficiently their common objectives [P7, P15]. Having a multi-agency task force that allowed collaborating with the several ministries concerned by malnutrition was also seen as a more persuasive way to convince the entire government that it was its responsibility to achieve MDG1by making the fight against malnutrition a national priority [P1, P2, P4, P5, P7, P8, P12, P15, P17].

“...in 2004, UN Nutrition Task Force in Laos was put in place... the Task Force works with ministries of Health, Education, Agriculture... this Task Force played a critical role in the emergence of the nutrition policy" [P17].

\subsection{Strategies Used by the External Actors to Influence the Emergence of the National Nutrition Policyin Laos}

Data show that four strategies were deployed by external actors in order to make an NNP enactment a national priority, including: generating, disseminating, and using evidence, assisting the government with a budget and technical expertise, providing decision-makers with opportunities to learn from other countries and building relationships with the key actor.

\subsubsection{Generating, Disseminating, and Using Evidence}

Using scientific evidence from surveys conducted in Laos was identified by the majority of the participants as an important strategy used by the Task Force to influence the emergence of the NNP.

Research projects aiming at producing Lao national health data started in the 1990s with financial and technical support by external actors, mainly UNICEF. External actors, in particular UN agencies, such as UNICEF and the WHO, were eager to promote scientific evidence-based culture in the health sector. Doing likewise led them to pinpoint malnutrition as a main problematic deserving more attention by the authorities [P1, P5, P6, P7, P15].

"Before the MICS III survey project in 2006 lead by UNICEF, the government was not yet aware of the problem of malnutrition, after that there was a recognition that malnutrition is the major problem in the country" [P15].

The literature was also used to convince the government that NNP was an effective tool for countries to achieve a significant reduction of the prevalence of malnutrition [P5, P7, P15].

The strategy of promoting the use of evidence also contained a component of transfer of knowledge toward a wider audience [P8, P10]. UNICEF and WHO organized conferences for decision-makers and all the actors working in the field on the problem of malnutrition. This aimed at increasing the number of organizations among stakeholders that became convinced about the need for a nutrition policy in the country. Making the government accept the idea of a policy was seen as needing pressure not only from external actors with their expertise and money but also from inside the government structure from the bottom up to the top [P1, P15, P17].

"UNICEF and WHO organized conferences not only for decision-makers but also for people working in the nutrition field to show the problem of malnutri- 
tion and convince them about the need of policy" [P1].

\subsubsection{Assisting the Government with a Budget and Technical Expertise}

Providing financial and technical assistance played a major role in the emergence of the NNP. These supports materialized through the search and funding of consultants and the offer of budgets for meetings between key actors involved in the design of the NNP.

Technical assistance started in 2006 when the fight against malnutrition was seen as a field that would very likely be prioritized by the government. This assistance was deemed by WHO necessary considering the lack of expertise in the government structure regarding the problem of malnutrition. As for the Minister of Health, he appointed a physician to be the first person in charge of a new unit specifically designed for the fight against malnutrition in the country [P1, P5, P17].

At that time, malnutrition was a new subject for the government. The government was focusing its efforts in the field of social/health policies on poverty reduction. There was no relevant plan or strategy to reduce the prevalence of malnutrition, besides actions related to poverty reduction [P1, P5, P6, P10, P18].

The person in charge of malnutrition first consulted the WHO's representation in Laos on how to build a structure for the fight against malnutrition in the country. In response, WHO agreed to provide a consultant and fund the coming of an external expert. It is the consultant who advised the Lao government to consider writing an NNP [P5, P7].

The acceptance of the proposition by the government led WHO to provide an additional budget to hire another consultant, from Vietnam, to help the Ministry of Health $(\mathrm{MOH})$ to develop the NNP. The MOH had asked WHO to find an expert from Vietnam, because of the many similarities between the political structures of Laos and Vietnam and the long history of collaboration between them [P5, P7, P15].

Halfway through the NNP development, the budget offered by WHO ended. The person in charge of malnutrition programs asked the FAO representation in Laos if it could take over the support that had been provided by WHO. Such a request addressed to the $\mathrm{FAO}$ was expected considering the knowing relationship that had grown between them over the years, thanks to many joint projects in the field of agricultural development and improvement of food and nutritional safety. A favorable answer was expected considering that the FAO also has the mandate to assist the government in its capacity building and in the development and implementation of policies or programs to improve the nutritional well-being of the population [P5, P10, P15, P17].

FAO effectively agreed to help. It provided a specific fund for developing the NNP. The budget allowed hiring another expert from Germany. FAO supported the MOH until the NNP was approved by the government [P5, P7].

"The WHO paid an expert to guide, they asked us to choose, at first we chose the expert from Vietnam... Vietnam made a lot of progress... we are close, the 
rules of politics are similar, in halfway, the budget from WHO was ended... After that, the FAO helped us in the development of nutrition policy" [P5].

The interviews with some governmental actors revealed that because supporting the development of public policies in their field is explicitly defined in the mandate of certain UN agencies, as the FAO, financial resources were available. UN agencies were, for that reason above all, more influential in the emergence of NNP compared to other external actors (NGOs and bilateral and multilateral cooperation) $[\mathrm{P} 5, \mathrm{P} 8, \mathrm{P} 15]$.

The involvement of bilateral and multilateral cooperation programs and several NGOs in the development of the NNP was therefore limited. They were expected to provide mainly technical advice based on their experience with fieldwork on nutrition in the community, particularly in rural areas [P4, P14, P19, P20].

\subsubsection{Providing Decision-Makers with Opportunities to Learn from Other Countries}

Providing decision-makers with opportunities to visit other countries has been proposed by governmental and external respondents as another key strategy used by UN agencies to convince the government about the relevance of writing a policy on nutrition. Attending high-level conferences or meetings, seminars, turned out to be effective in making decision-makers discover the political benefit of enacting policies [P1, P2, P3, P5, P6, P14, P15, P20].

"Given the chance to decision-makers sharing knowledge with other countries or to learn, to see how other countries have done and adapted to our country... It was important" [P3].

$\mathrm{UN}$ agencies considered that giving government staff the opportunity to discuss other countries' experiences should be an effective way to help them to better anticipate challenges in translating policies into effective actions and to better imagine relevant solutions to overcome the challenges considering the context of the country [P3, P15]. As stated by the government staff interviewees, visiting Vietnam, in particular, helped them to realize how important nutrition-focused institutions, as the Nutrition Institute, the Nutritional laboratory, or the National Nutrition Committee under the leadership of a Deputy Minister was and how their emergence could only take place with an enactment of an NNP. The Vietnamese Nutrition Policy was to become the main inspiration for the Lao government [P5, P7]. The successes of the Vietnamese NNP in reducing child malnutrition in Vietnam were seen by the Lao government as an example of the capacity of the one-party state to achieve a major social goal and get acknowledgment for this accomplishment [P5, P6, P7, P15].

Several government staff interviewees also highlighted the fact that these trips were decisive to make decision-makers realize that an NNP was a key ingredient of the capacity of a ministry to become a leader of multi-sectorial initiative as the one needed to reduce malnutrition in the country [P5, P7, P15, P17]. 


\subsubsection{Building Relationships with the Key Actors}

According to some external participants, the last strategy was deployed by UN agencies to convince the government to work on an NNP: forming friendly interpersonal relationships between senior staff of UN agencies and high-ranked $\mathrm{MOH}$ staff. Friendly relationships meant a degree of relationship that allowed informal meetings where discussions on malnutrition could take place. These informal meetings were seen as an effective strategy because they allowed rapidly discussing solutions to problems on specific issues without passing through the complex administrative procedure imposed by the state bureaucracy [P14, P18, P19, P20].

"Having a good relationship with the high authority in $\mathrm{MOH}$, allowed them [UN agencies] to have more chance of discussing the policy with the key actors, for example by meeting by chance or the meeting could be organized informally, which allowed them to emphasize and explain more clearly about the proposition" [P20].

\section{Discussion}

\subsection{The Triggering Role of the Millennium Development Goals}

Governments that adopted the MDGs were required to monitor and evaluate whether the MDG-targeted policies and programs were positively affecting health goals [34]. To help monitor progress, the UN provided scientifically robust and ethically acceptable indicators that had to be used, in line with the support provided to actions that characterize good governance around the world [35]. This had some sideeffects. The MDGs contributed to the adoption by the countries that had prioritized the MDG goals, of a culture of evaluation, hence an internal process of policymaking that took into consideration scientific evidence. For many governments, this was a change of paradigm. Moreover, this culture of evaluation led governments and their ministries to realize that addressing complex health problems through inter-sectorial programs was often more effective and more efficient [36].

In the field of nutrition, effectively, the MDGs brought major changes. The MDGs mid-term progress reports had shown that Laos was making very slow progress in the reduction of malnutrition. They also showed that nutrition should now be considered as the main driver to achieve other MDGs, instead of just being the main beneficiary from the reduction of poverty and food security [32]. This rising awareness of the central role of nutrition in human well-being at the government level arouses its interest to design and implement a policy based on intersectional evidence to address the problem of malnutrition. A dynamic was triggered. The Lao policy on nutrition would rest on science from now on. Its dynamic would rest on the collaboration of actors coming from all concerned development sectors, health, agriculture, education, social development sectors, and others, that would be led to collaborate. The conditions for the birth of an NNP had been brought together. 
In Laos as in many countries, the MDGs were a key trigger to put nutrition on the top of the policy agenda of many developing countries [37] [38].

Above all, the MDGs provided a road map and became a reference guide to the emergence of national policies that would encompass broader priority development issues than just a preoccupation for the short-term improvement of economic indicators [39].

\subsection{United Nations Agencies: The Key Coalition}

The entire process deployed by the UN agencies aimed at convincing the government that scientific knowledge should be the basis of a national policy on nutrition. For that matter, UN Agencies were, before the emergence of the NNP, supportive of researchers willing to design and conduct national health surveys that allowed the government to learn more about malnutrition in the country [14] [17] [40].

Yet, it was the budget and technical expertise of consultants that were the decisive elements to convince the government to take the leadership of the fight against malnutrition. In Laos as elsewhere, external consultants have become key actors in policy-making processes [41] [42] [43].

One notes the facilitating effect of sociocultural factors beyond the expertise of the experts, in order to make them fully influential. The request by the Lao government to be provided with a Vietnamese consultant aimed at making the communication between both parts easier. Laos and Vietnam are bound through a special history that rests on the collaboration of the communist parties in their fight for power in both countries, and thereafter, the "special relations" formalized by the 25 years Treaty of Friendship and Cooperation signed in 1977 [44]. Collaboration at the government level was intense. It laid the ground for deep mutual understanding that could only benefit the emergence of a public policy in Laos inspired by what had been done in Vietnam.

This study also found that an effective strategy to make the government produce NNP consisted of providing key government staff with opportunities to see what had been done in other countries. The objective of observing foreign experiences helped to weigh the use of scientific evidence by some dose of realism imprinted by real-life factors. This strategy has been shown to be effective indeed in influencing either directly or indirectly the adoption of a number of public policies [45]. Normatively, lesson-drawing mostly occurs among countries with a similar level of development of economic and political context [46].

Our results show that informal relationships played a role in the emergence of nutrition policy in Laos. Laos is a poorly populated country. It has the lowest population density in Southeast Asia. Opportunities for informal contacts are therefore high. The impact of informal relationships, i.e. relationships outside the rigid frame of formal meetings and formal lobbying activities, is often underestimated when examining policy processes. However, it has been shown that the provision of money, expertise, and scientific evidence is not sufficient to make 
decision-makers inclined to develop a public policy [47]. The informal relationship could give a sense of living a moment of privileged familiarity and hospitality has a psychological effect that can be exploited by a potential collaborator of decision-makers [48]. The UN relied on this informal contact at dinners, parties and other occasions, to reinforce the gains perceived from discussions at formal meetings.

Finally, one notes that UN agencies in developing countries have the mandate to provide support to governments in order to help them to achieve more effectively and efficiently their national priorities. The UN Nutrition Task Force actions were coherent with the global way UN agencies tend to act in LMICs. The concerned Agencies in Laos sought to fulfill their mandate by focusing not only on the expected benefits of actions based on their complementarities but also on the convincing power brought by having shared strategies. This preoccupation constantly underpinned their contribution to the fight against malnutrition. Among their shared strategies were the expertise and financial support that turned out to be key arguments to convince the government about the relevance of making the fight against malnutrition a national priority. Nutrition is a multisectoral field that requires not only a high level of expertise in order to design relevant interventions, but also a fast-moving one. New knowledge in nutrition and an environment that is constantly changing will require regular adaptation of the NPP to new realities. We can therefore hypothesize that the maintenance of the task force and of its accomplice collaboration with the government will be an important element for the NNP to continue bringing positive results to the nutrition status of the Lao population.

\subsection{Limitations}

We recognize that our findings may not be generalizable to other policy contexts or policy subsystems. Factors involved in a policy building process are numerous and extraordinarily varied. For example, in other countries, many actors who apparently played little role in the single-party state that is Lao PDR might play a crucial role in policy processes, such as the private sector, the media, the civil society or nonprofit organizations [21].

Some limitations regarding our methodology should also be noted. The use of a sampling approach largely based on reasoned choice poses a risk of representative bias. However, this sampling approach was supplemented by a snowball-sampling component. Moreover, access to key informants was sometimes hindered by the fact that the nutrition policy of Lao PDR had been implemented in 2008. Several potential participants, who were identified, especially among external actors, had changed their position. Most of them could be reached by phone and video conferences but some had to be substituted by people who joined the organizations after 2008, who were considered as knowledgeable enough to express what had happened in their organizations at the time of the emergence of the nutrition policy. 


\section{Conclusion}

In this study, we specifically focused on the external advocacy coalition and strategies used to influence the emergence of NNP in Laos. Our findings showed that the advocacy coalition of UN agencies played a crucial role in the emergence of NNP in Laos, but that this role, to be effective, probably required the window of opportunity brought by an external event, the MDGs and the commitment by the government to reach these goals.

\section{Conflicts of Interest}

The authors declare no conflicts of interest regarding the publication of this paper.

\section{References}

[1] Black, R.E., Victora, C.G., Walker, S.P., Bhutta, Z.A., Christian, P., De Onis, M., Ezzati, M., Grantham-McGregor, S., Katz, J., Martorell, R. and Uauy, R. (2013) Maternal and Child under Nutrition and Overweight in Low-Income and Middle-Income Countries. The Lancet, 382, 427-451. https://doi.org/10.1016/S0140-6736(13)60937-X

[2] World Health Organization (2021) Malnutrition. https://www.who.int/news-room/fact-sheets/detail/malnutrition

[3] World Health Organization (2013) Global Nutrition Policy Review: What Does It Take to Scale Up Nutrition Action? World Health Organization, Geneva. https://www.who.int/nutrition/publications/policies/global_nutrition_policyreview. pdf

[4] Ministry of Health (2008) National Nutrition Policy. https://extranet.who.int/nutrition/gina/sites/default/filesstore/LAO\%202008\%20Nat ional\%20Nutrition\%20Policy.pdf

[5] Sisouphanthong, B., Xaovanna. V. and Intharack T. (1997) Report on Multiple Indicator Cluster Survey (MICS). https://mics.unicef.org/surveys

[6] Kaufmann, S. (2003) FAO-Nutrition Country: Laos. http://www.fao.org/3/bc651e/bc651e.pdf

[7] Rim, H.J., Chai, J.Y., Min, D.Y., Cho, S.Y., Eom, K.S., Hong, S.J., Sohn, W.M., Yong, T.S., Deodato, G., Standgaard, H. and Phommasack, B. (2003) Prevalence of Intestinal Parasite Infections on a National Scale among Primary Schoolchildren in Laos. Parasitology Research, 91, 267-272. https://doi.org/10.1007/s00436-003-0963-x

[8] Ministry of Planning and Investment, Ministry of Health, and United Nations Children's Fund (2006) Lao PDR-Multiple Indicator Cluster Survey 2006.

https://mics.unicef.org/surveys

[9] Ministry of Health (2012) Report on Health Action Plan Implementation for 2011-2012 (in Lao). Ministry of Health, Vientiane.

[10] Paphassarang, C., Wahlstrom, R., Phoummalaysith, B., Boupha, B. and Tomson, G. (2002) Building the National Drug Policy on Evidence-A Cross Sectional Study on Assessing Implementation in Lao PDR. Southeast Asian Journal of Tropical Medicine and Public Health, 33, 647-653.

[11] Jönsson, K., Phoummalaysith, B., Wahlström, R. and Tomson, G. (2015) Health Policy Evolution in Lao People's Democratic Republic: Context, Processes and Agen- 
cy. Health Policy and Planning, 30, 518-527.

https://doi.org/10.1093/heapol/czu017

[12] Clavier, C. and de Leeuw, E. (2013) Health Promotion and the Policy Process. Oxford University Press, Oxford. https://doi.org/10.1093/acprof:oso/9780199658039.001.0001

[13] Lemieux, V. (2003) L'étude des politiques publiques: Les acteurs et leur pouvoir $\left(2^{\mathrm{e}}\right.$ éd.). Les Presses de l'Université Laval, Québec.

[14] Michaud-Létourneau, I., Gayard, M. and Pelletier, D.L. (2019) Translating the International Code of Marketing of Breast-Milk Substitutes into National Measures in Nine Countries. Maternal \& Child Nutrition, 15, Article No. e12730. https://doi.org/10.1111/mcn.12730

[15] Etiaba, E., Uguru, N., Ebenso, B., Russo, G., Ezumah, N., Uzochukwu, B. and Onwujekwe, O. (2015) Development of Oral Health Policy in Nigeria: An Analysis of the Role of Context, Actors and Policy Process. BMC Oral Health, 15, Article No. 56. https://doi.org/10.1186/s12903-015-0040-8

[16] Gautier, L. and Ridde, V. (2017) Health Financing Policies in Sub-Saharan Africa: Government Ownership or Donors' Influence? A Scoping Review of Policymaking Processes. Global Health Research and Policy, 2, Article No. 23. https://doi.org/10.1186/s41256-017-0043-x

[17] Khan, M.S., Meghani, A., Liverani, M., Roychowdhury, I. and Parkhurst, J. (2018) How Do External Donors Influence National Health Policy Processes? Experiences of Domestic Policy Actors in Cambodia and Pakistan. Health Policy and Planning, 33, 215-223. https://doi.org/10.1093/heapol/czx145

[18] Herberholz, C. (2020) The Role of External Actors in Shaping Migrant Health Insurance in Thailand. PLOS ONE, 15, e0234642.

https://doi.org/10.1371/journal.pone.0234642

[19] Koduah, A., van Dijk, H. and Agyepong, I.A. (2015) The Role of Policy Actors and Contextual Factors in Policy Agenda Setting and Formulation: Maternal Fee Exemption Policies in Ghana over Four and a Half Decades. Health Research Policy and Systems, 131, Article No. 27. https://doi.org/10.1186/s12961-015-0016-9

[20] Storeng, K.T., Palmer, J., Daire, J. and Kloster, M.O. (2019) Behind the Scenes: International NGOs' Influence on Reproductive Health Policy in Malawi and South Sudan. Global Public Health, 14, 555-569. https://doi.org/10.1080/17441692.2018.1446545

[21] Sabatier, P.A. and Weible, C.M. (2007) Theory of the Policy Process. 2nd Edition, Westview Press, Boulder.

[22] Cullerton, K., Donnet, T., Lee, A. and Gallegos, D. (2018) Effective Advocacy Strategies for Influencing Government Nutrition Policy: A Conceptual Model. International Journal of Behavioral Nutrition and Physical Activity, 15, Article No. 83. https://doi.org/10.1186/s12966-018-0716-y

[23] Cairney, P. (2012) Understanding Public Policy: Theories and Issues. Palgrave Macmillan, London.

[24] Lemieux, V. (1998) Les Coalitions: Liens, transactions et contrôles. Presses Universitaires de France, Paris.

[25] Sabatier, P.A. and Weible, C.M. (2014) Theories of Policy Process. 3rd Edition, Westview Press, Boulder.

[26] Fortin, M.F. and Gagnon, J. (2016) Fondement et étapes processus de recherche: Methode quantitatives et qualitatives (3e ed.). Chenelière Education, Quebec. 
[27] Biernacki, P. and Waldorf, D. (1981) Snowball Sampling: Problems and Techniques of Chain Referral Sampling. Sociological Methods \& Research, 10, 141-163. https://doi.org/10.1177\%2F004912418101000205

[28] Miles, M.B., Huberman, A.M. and Saldana, J. (2014) Qualitative Data Analysis: A Methods Source Book. 3rd Edition, Sage Publications, Los Angeles.

[29] Fortin, M.F. (2010) Fondements et étapes du processus de recherche: Méthodes quantitatives et qualitatives. 2nd Edition, Chenelière Éducation, Quebec.

[30] Committee for Planning and Investment (2006) The Sixth National Socio-Economic Development Plan (2006-2010).

https://www.preventionweb.net/files/15958_6thnsedplaos.pdf

[31] United Nations (2004) Millennium Development Goals Progress Report Lao PDR 2004.

https://www.la.undp.org/content/lao_pdr/en/home/library/mdg/mdg-compact-for-l ao-pdr.html

[32] United Nations (2008) Millennium Development Goals: 2008 Progress Report. https://laopdr.un.org/13300-millennium-development-goals-2008-progress-report

[33] The Government of Lao PDR (n.d.) The 2004-2006 National Growth and Poverty Eradication Strategy.

[34] World Health Organization (2005) Health and the Millennium Development Goals. https://www.who.int/hdp/publications/mdg_en.pdf?ua=1

[35] Wagstaff, A., Claeson, M., Hecht, R.M., Gottret, P. and Fang, Q. (2006) Disease Control Priorities in Developing Countries. 2nd Edition, The International Bank for Reconstruction and Development/The World Bank, Washington DC and Co-Published by Oxford University Press, New York.

[36] Waage, J., Banerji, R., Campbell, O., Chirwa, E., Collender, G., Dieltiens, V., Dorward, A., Godfrey-Faussett, P., Hanvoravongchai, P., Kingdon, G. and Little, A. (2010) The Millennium Development Goals: A Cross-Sectoral Analysis and Principles for Goal Setting after 2015: Lancet and London International Development Centre Commission. The Lancet, 376, 991-1023. https://doi.org/10.1016/S0140-6736(10)61196-8

[37] Pelletier, D.L., Menon, P., Ngo, T., Frongillo, E.A. and Frongillo, D. (2011) The Nutrition Policy Process: The Role of Strategic Capacity in Advancing National Nutrition Agendas. Food and Nutrition Bulletin, 32, S59-S69. https://doi.org/10.1177\%2F15648265110322S203

[38] Jat, T.R., Deo, P.R., Goicolea, I., Hurtig, A.K. and San Sebastian, M. (2013) The Emergence of Maternal Health as a Political Priority in Madhya Pradesh, India: A Qualitative Study. BMC Pregnancy and Childbirth, 13, Article No. 181. https://doi.org/10.1186/1471-2393-13-181

[39] United Nations (2016) World Economic and Social Survey 2014/2015: Learning from National Policies Supporting MDG Implementation.

https://www.un.org/en/development/desa/policy/wess/wess_archive/2015wess_full_ en.pdf

[40] The National Statistical Center and UNICEF (2000) Multiple Indicator Cluster Survey 2000. https://mics.unicef.org/surveys

[41] Saint-Martin, D. (1998) The New Managerialism and the Policy Influence of Consultants in Government: An Historical-Institutionalist Analysis of Britain, Canada and France. Governance, 11, 319-356. https://doi.org/10.1111/0952-1895.00074

[42] Howlett, M. and Migone, A. (2013) Policy Advice through the Market: The Role of External Consultants in Contemporary Policy Advisory Systems. Policy and Society, 
32, 241-254. https://doi.org/10.1016/j.polsoc.2013.07.005

[43] Saguin, K. (2018) Policy Consulting in Developing Countries: Evidence from the Philippines. Journal of Asian Public Policy, 11, 188-205.

https://doi.org/10.1080/17516234.2018.1462559

[44] Stuart-Fox, M. (1980) Laos: The Vietnamese Connection. In: Suryadinata, L., Ed., Southeast Asian Affairs 1980, 191-209.

[45] Rose, R. (1993) Lesson Drawing in Public Policy: A Guide to Learning across Time and Space. Chatham House, London.

[46] Asare, B.E. and Studlar, D.T. (2009) Lesson-Drawing and Public Policy: Secondhand Smoking Restrictions in Scotland and England. Policy Studies, 30, 365-382. https://doi.org/10.1080/01442870902863935

[47] Cullerton, K. (2017) An Exploration of the Factors Influencing Public Health Nutrition Policymaking in Australia. Ph.D. Dissertation, Queensland University of Technology, Brisbane.

[48] Maneechay, M. and Pongpirul, K. (2015) Informal Relationship Patterns among Staff of Local Health and Non-Health Organizations in Thailand. BMC Health Services Research, 15, Article No. 113. https://doi.org/10.1186/s12913-015-0781-8 